\title{
Corrosion-fatigue failure of tractor trailers metal materials in aggressive environments
}

\author{
Popovych P. ${ }^{1}$, *Poberezhny L. ${ }^{2}$, Shevchuk $O .^{1}$, Murovanyi $I^{3}{ }^{3}$, Poberezhna L. ${ }^{2}$, Hrytsanchuk A. ${ }^{2}$ and Koval Y. ${ }^{1}$ \\ 1 Ternopil National Economic University, Ukraine \\ ${ }^{2}$ Ivano-Frankivsk National Technical University of Oil and Gas, Ukraine \\ ${ }^{3}$ Lutsk National Technical University, Ukraine \\ E-mail: lubomyrpoberezhny@gmail.com
}

The processes of corrosion-fatigue failure of materials in contact with mineral fertilizers are insufficiently studied. As a result of joint influence of atmospheric corrosion and mechanical loads, about 70 to $80 \%$ of machine parts get out of order, 20 to $25 \%$ of which are failures caused by operating overload due to the strength loss because of atmospheric corrosion. A large part of metal structures of agricultural vehicles used to transport mineral fertilizers is under the direct influence of aggressive environments and dynamic loads that occur $d u$ ring the motion by field roads. Saturated solutions of the most aggressive working environments used in agricultural production, in particular ammonium sulphate and nitrophosphate are investigated to reduce fatigue resistance of ordinary steels groups - St 3 and St5 and quality steels - 10 Steel, 15 Steel, 20 Steel, 25 Steel when loaded at all levels. The fatigue endurance limit decreases in comparison with air up to 2.02 times in a solution of ammonium sulphate, and to 2.32 times in a solution of nitrophosphate. In organic fertilizer environments, compared to distilled water, the conditional fatigue endurance limit increased to $9 \%$. The properties of the given materials as an inhibitor of corrosion-fatigue failure were discovered and proved.

\section{INTRODUCTION}

The key factors of fatigue and corrosion-fatigue failure of transport machines metal structures used in agricultural production determine the state of working surfaces, load parameters, environments aggressiveness degrees in consideration of the different kinds of fertilizer, weather conditions, etc. [1-11]. On examining the technical state of agricultural machinery after 3 years of operation, it is observed that corrosion contributes to approximately $80 \%$ of all mechanical failures of assembly units [3, 5-11] (Fig. 1 and 2). The corrosion fatigue failure is the result of additive effects of service loads, environments, and thermodynamic lability of metal structures materials. Corrosion damages and light-gage sheet metal failures change a state of workpiece surface and intensify the wear processes. They significantly degrade tribotechnical properties and corrosion processes, causing a simultaneous decrease in fatigue strength. As a result, the reliability and durabi- lity of vehicles are significantly reduced. Similar processes occur when operating gas pipelines in corrosive environments [12-18], because of one of the most common materials for oil and gas pipelines is carbon steels.

The processes of corrosion-fatigue failure of materials in contact with organic and mineral fertilizers are insufficiently studied. The absence of reliable data makes it difficult to develop new effective methods of corrosion protection of agricultural fertilizing machines.

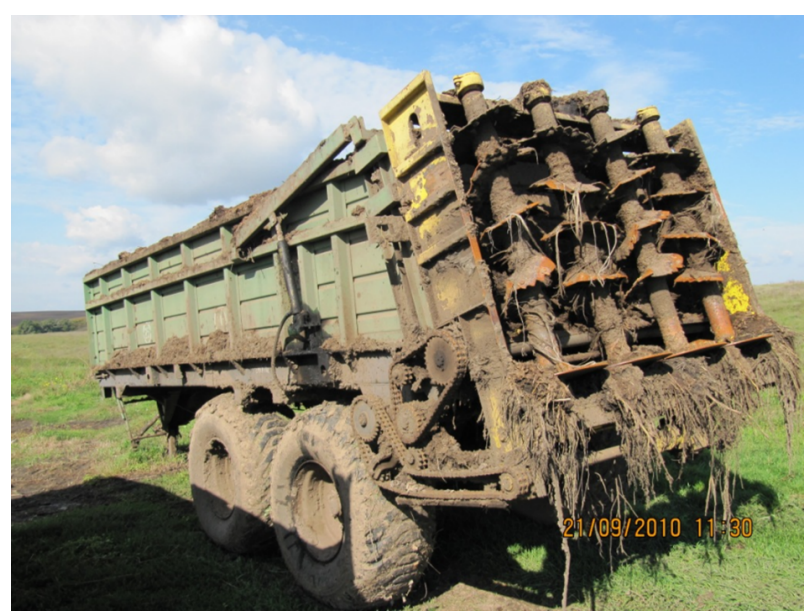

a)

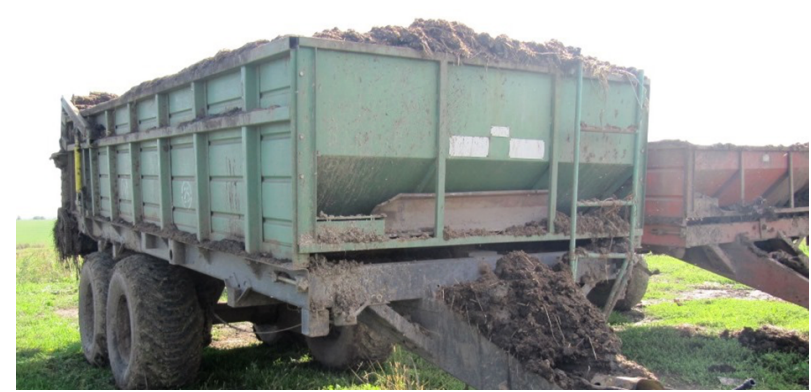

b)

Fig. 1. Corrosion-fatigue failures of machine units used in agricultural production 


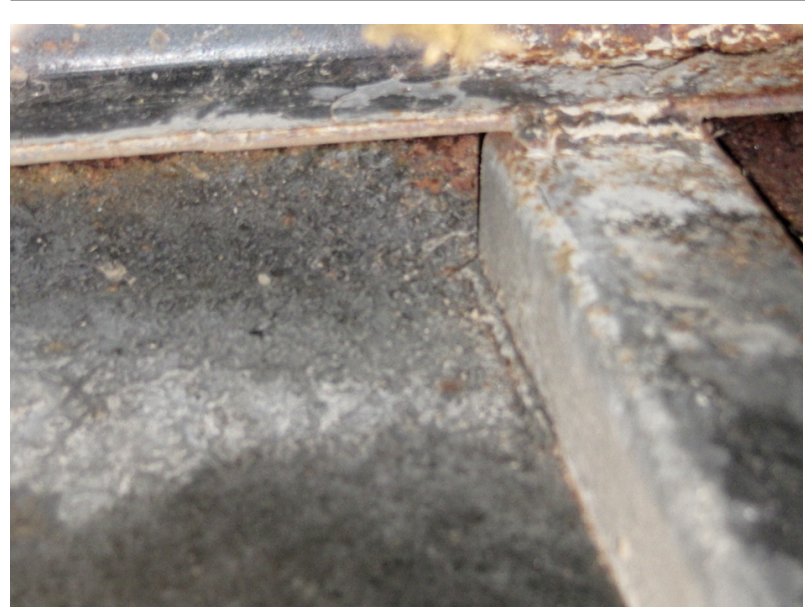

a)

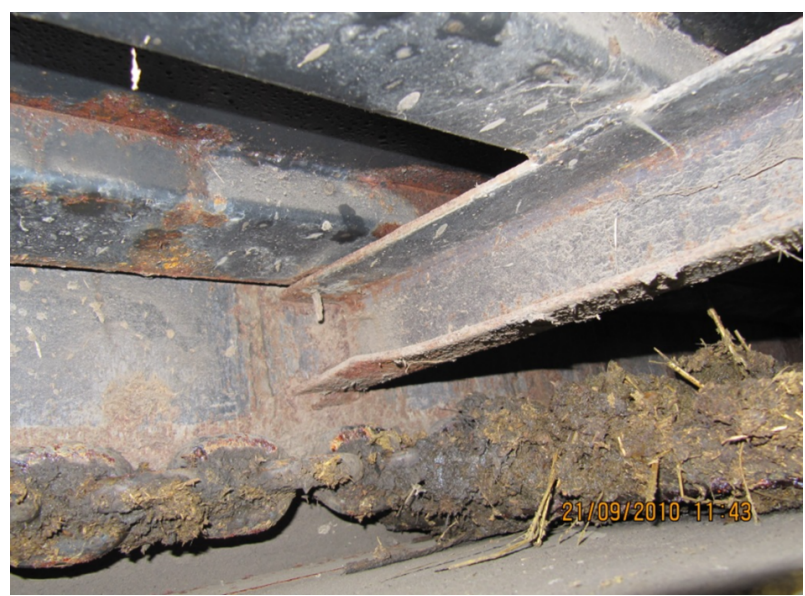

b)

Fig. 2. Welded fatigue failures of light-gage sheet metal structures of trailers

In particular, in $[1,19,20]$, two steels are studies without taking into account the fact that for manufacturing metal structures of this class machinery, the whole range of standard and quality steels are applied. There is a need for experimental research of the whole range of metal materials of tractor-trailers, fertilizing machines, etc. under the influence of corrosive agricultural environments. The results of such research could be used as input data for the objective and quantitative assessment of operability parameters of the given type vehicles.

\section{MATERIALS AND METHODS}

For fatigue and corrosion fatigue tests [21-22], the cylindrical specimens (Fig. 3) with a diameter of $10 \mathrm{~mm}$ made of standard steels St3, St5 and quality steels 10 Steel, 15 Steel, 20 Steel, 25 Steel under supply condition were used. Chemical composition of tested steels in Table 1. The working body was an aluminum oxide wheel ЭB25SMIK. After turning, the grinding allowance was $0.35 \mathrm{~mm}$. Rotation velocity of a specimen was $3 \mathrm{~m} \mathrm{~min}^{-1}$, linear velocity of a stone $-30 \mathrm{~m} \mathrm{~s}^{-1}$, depth of grinding during the final passage $-0.005 \mathrm{~mm} / \mathrm{rev}$, surface roughness $R_{z}=2.5 \mu \mathrm{m}$.
To eliminate the traces of mechanical grinding and to provide the fine precision of obtained results, the working area of all specimens before testing was polished using a sandpaper and diamond pastes with different dispersion. The same type of manufacturing technology was applied for manufacturing the batch of specimens (Fig. 3). Therefore, the specimen designation was carried out on both specimen holders. The precision of measurements of the prepared specimens working area was $0.01 \mathrm{~mm}$.

Distilled water as a standard test condensate of water or rainwater, saturated solutions of ammonium sulphate and nitrophosphate, mixed liquid manure of cattle and pigs in proportion $1 / 2$ acted as corrosive environments $[1,4,19,20]$. Acidity levels of environments before and after the experimental studies were measured by $\mathrm{pH}$ meter I-160M. Fatigue tests were carried out on the equipment IMA-5. The specimens were loaded by the scheme of rotating bend; cycle asymmetry coefficient was $\mathrm{R}=-1$ [19-22]. A fast-speed counting device before fracture $N$ fixed the number of cycles. Based on obtained data, the Wohler curves were built. Tests started at $2 / 3 \sigma_{6}$, incrementally reducing the value to the limit of endurance $\sigma_{-1}$ within the framework of research $\left(10^{7}\right.$ cycles - when tested in air, $5 \cdot 10^{7}$ cycles - in environments under study).

Tab. 1. Chemical composition of tested steels

\begin{tabular}{|l|c|c|c|c|c|c|c|c|c|c|}
\hline & $\mathbf{C}$ & $\mathbf{S i}$ & $\mathbf{M n}$ & $\mathbf{N i}$ & $\mathbf{P}$ & $\mathbf{S}$ & $\mathbf{C r}$ & $\mathbf{A s}$ & $\mathbf{C u}$ & $\mathbf{F e}$ \\
\hline Steel 10 & $0.07-0.14$ & $0.17-0.37$ & $0.35-0.65$ & $<0.25$ & $<0.035$ & $<0.04$ & $<0.015$ & $<0.08$ & $<0.25$ & $\sim 98$ \\
\hline Steel 15 & $0,12-0,19$ & $0.17-0.37$ & $0,35-0,65$ & $\leq 0,30$ & $\leq 0,035$ & $\leq 0,040$ & $\leq 0,15$ & $<0.08$ & $\leq 0,20$ & $\sim 98$ \\
\hline Steel 20 & $0.17-0.24$ & $0.17-0.37$ & $0.35-0.65$ & $<0.25$ & $<0.04$ & $<0.04$ & $<0.25$ & $<0.08$ & $<0.25$ & $\sim 98$ \\
\hline Steel 25 & $0,22-0,30$ & $0,17-0,37$ & $0,50-0,80$ & $<0.25$ & $\leq 0,035$ & $\leq 0,040$ & $<0.25$ & $<0.08$ & $\leq 0,25$ & $\sim 98$ \\
\hline St3 & $0,25-0,32$ & $0.05-0.15$ & $0.4-0.65$ & - & $<0.04$ & $<0.05$ & $<0.03$ & $<0.08$ & $<0.3$ & $\sim 98$ \\
\hline St5 & $0.47-0.55$ & $0.17-0.37$ & $0.5-0.8$ & - & $<0.035$ & $<0.04$ & - & - & - & $\sim 98$ \\
\hline
\end{tabular}




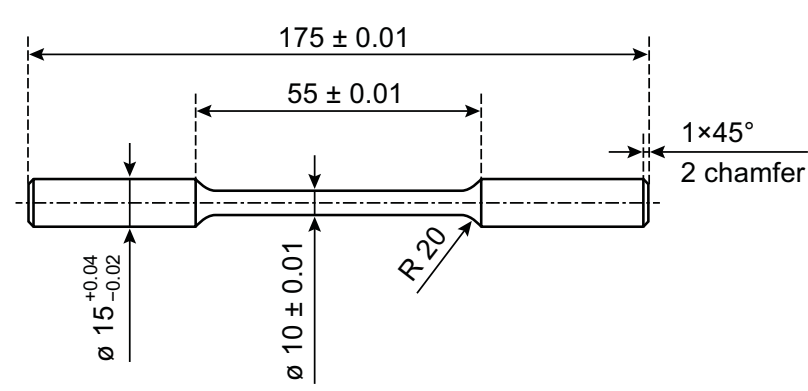

Fig. 3. General appearance of specimen for fatigue tests

As a research material, 5-15 specimens at a level of stress $(0.95 \ldots 1.05) \cdot \sigma_{-1}$ were used. Based on the research results, the fatigue limit was determined. Two specimens under study remained non-failed after reaching the specified database of testing. After examining 10-15 specimens, the fatigue curves were built $[21,22]$.

\section{RESULTS AND DISCUSSION}

The study of ordinary steels St3, St5 and quality steels - 10 Steel, 15 Steel, 20 Steel, 25 Steel proved that in the whole range of loads, the resistance of quality steels to corrosion-fatigue failure in environments of mineral fertilizers, as compared with air and standard test environment condensate (rainwater), was significantly reduced. (Fig. 1, Tab. 2). Less intense impact on the steels fatigue endurance limit of two groups of mixed manure under study compared to mineral fertilizers was noticed. However, the negative impact of environment on the conditional fatigue endurance limit in comparison with the standard test rainwater was not noticed.

The destruction of specimens during rotational bending tests is due to the inability to avoid contact of the conjugated fracture surfaces, which will be formed due to the growth of the fatigue crack arising from the lateral surface of the samples under the influence of alternating cyclic loads. Therefore, the fractures were studied at different, minimum possible levels of maximum stress, in order to minimize the effects of the specified contact at the final stage of destruction of the sample.

The cracks in the air originated in one (at least two) places along the perimeter of the specimen and the crescent front extended into the depth of its cross section (Fig. 5a). At the same time, the festoons were created at the fracture, across which fatigued grooves were located (Fig. 5b).

The boundaries between the adjacent festoons were indicated at the fracture by ridges of the ductile separation, which often had traces of riveting due to the discrepancy of troughs and ridges when contacting the edges of the crack in the load cycle. The step of these grooves increased as the crack progressed from the outer surface of the specimen to its final destruction, which was ductile by the origin of the cavities, their subsequent growth, and the fusion with the formation on the surface of the typical fossa relief. A significant change in the mechanism of destruction was found under the influence of the studied media. The number of fatigue cracks on the lateral surface of the samples increases significantly, their propagation front changes. As a rule, these cracks extended deep into the cross section of specimens in the form of wedges (Fig. 6a). The higher resolution of the fractures clearly identified the elements of inter- and trans-granular. fracture, a significant secondary cracking along the grain boundaries (Fig. 6b,c).

Due to the destruction along the perlite boundaries in common with the ferrite boundaries, the perlite structure can be observed. This specificity of fatigue destruction leads to a decrease in the limit of fatigue with increasing perlite content. the results obtained in the study are in good agreement with the works [23-25]. Similar mechanisms of fatigue and corrosion-fatigue fracture are observed in tubular steels of such chemical composition [26-30] under difficult operating conditions [31-32]. It can be concluded that the detection of the boundaries of the perlite plates became possible only because of the influence of the aggressive components of the investigated media for the reason that such destruction was not observed in the air. When testing samples in distilled water, the classic fatigue fracture mechanism with elements of inter granular cracking prevailed. This is the reason why they have a significantly lower effect on the conditional fatigue limit of Steel 15 compared to the mineral fertilizers obtained in the solutions.

Tab. 2. Fatigue endurance limits of metal structure materials in working environments (MPa)

\begin{tabular}{|l|c|c|c|c|c|}
\hline \multirow{2}{*}{ Steel } & \multirow{2}{*}{ Air } & \multirow{2}{*}{ Organic fertilizer } & \multirow{2}{*}{ Distilled water } & \multicolumn{2}{|c|}{ Mineral fertilizers } \\
\cline { 5 - 6 } & & & & Ammonium sulphate & Nitrophosphate \\
\hline St3 & 197 & 139 & 121 & 93 & 85 \\
\hline St5 & 208 & 146 & 127 & 98 & 89 \\
\hline 10 Steel & 192 & 135 & 124 & 95 & 90 \\
\hline 15 Steel & 202 & 143 & 136 & 102 & 90 \\
\hline 20 Steel & 207 & 147 & 135 & 104 & 96 \\
\hline 25 Steel & 219 & 156 & 143 & 111 & 83 \\
\hline
\end{tabular}




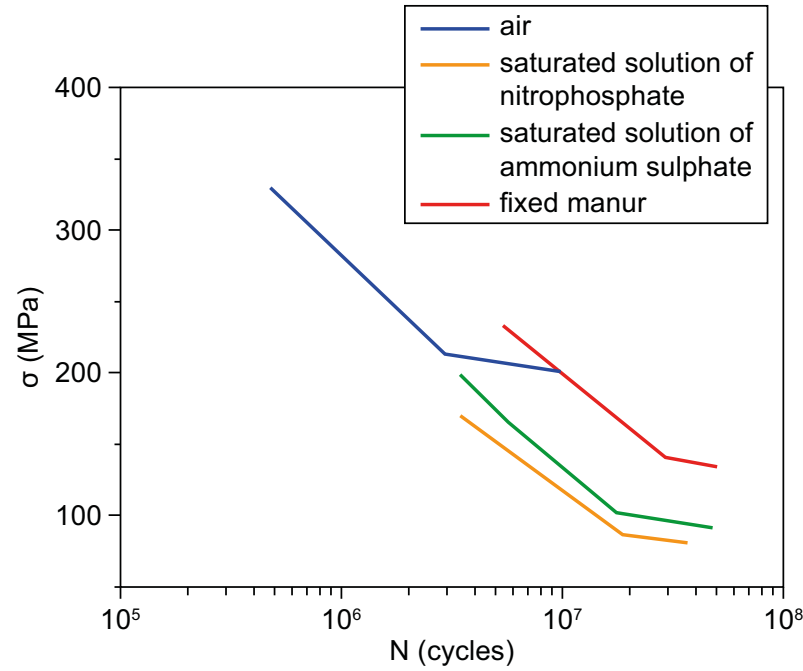

a)

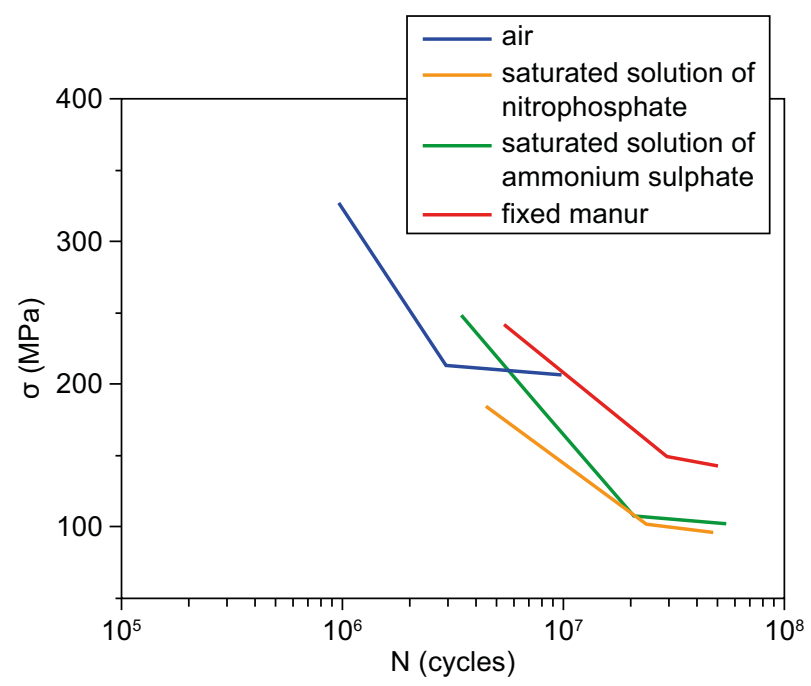

c)

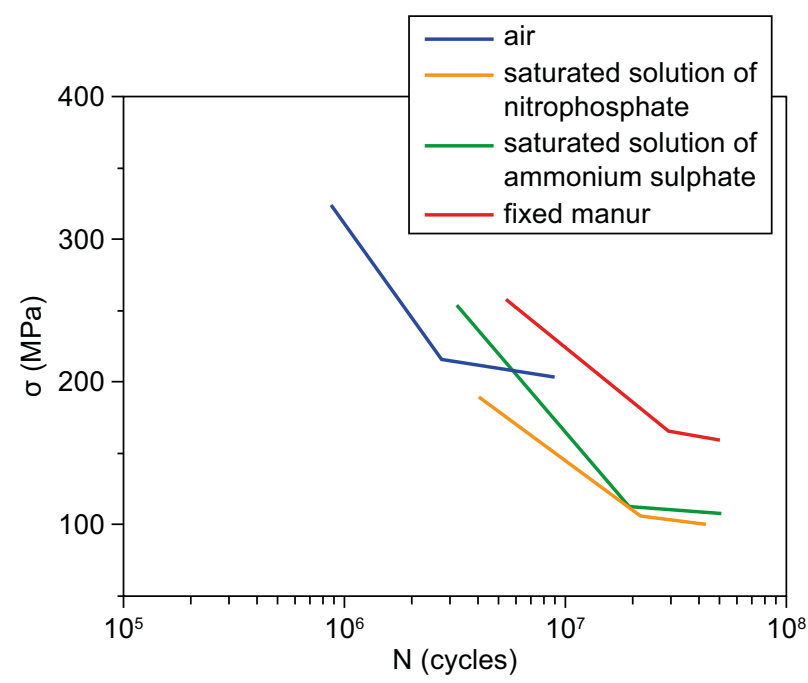

e)

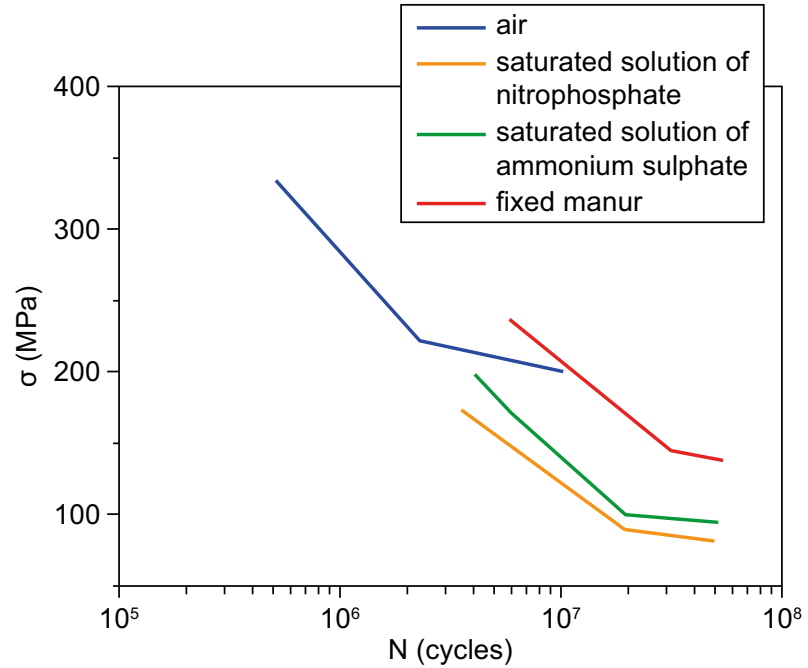

b)

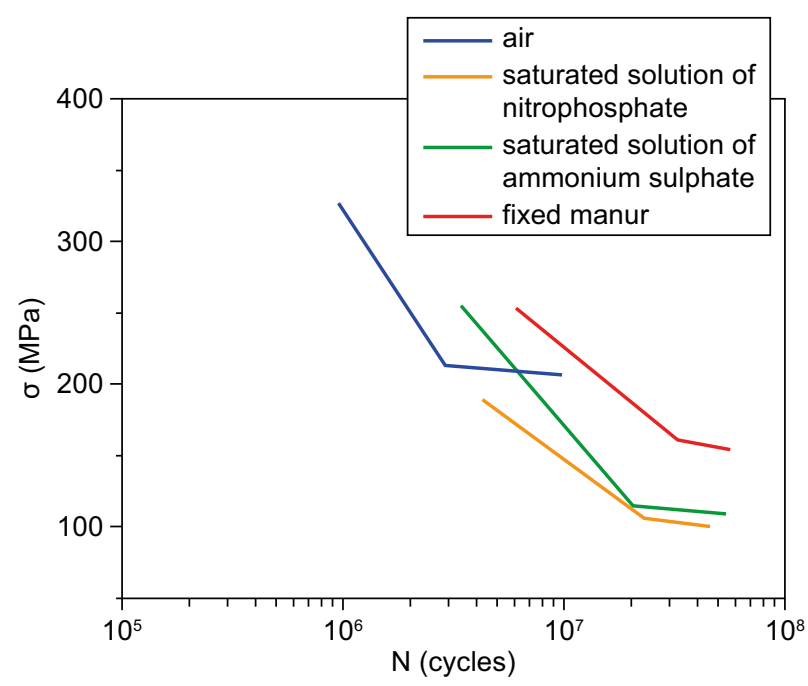

d)

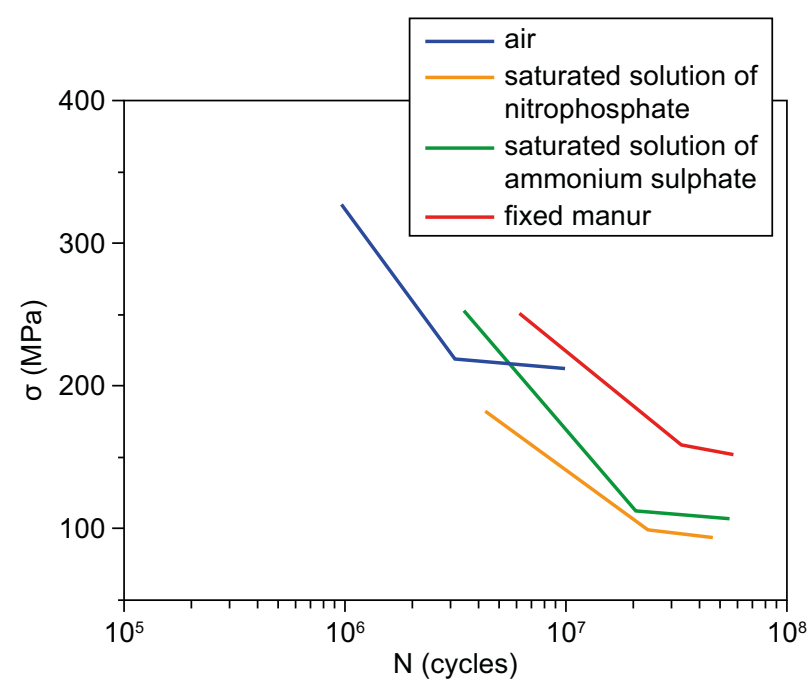

f)

Fig. 4. Fatigue curves of standard steels and quality steels in working environments 


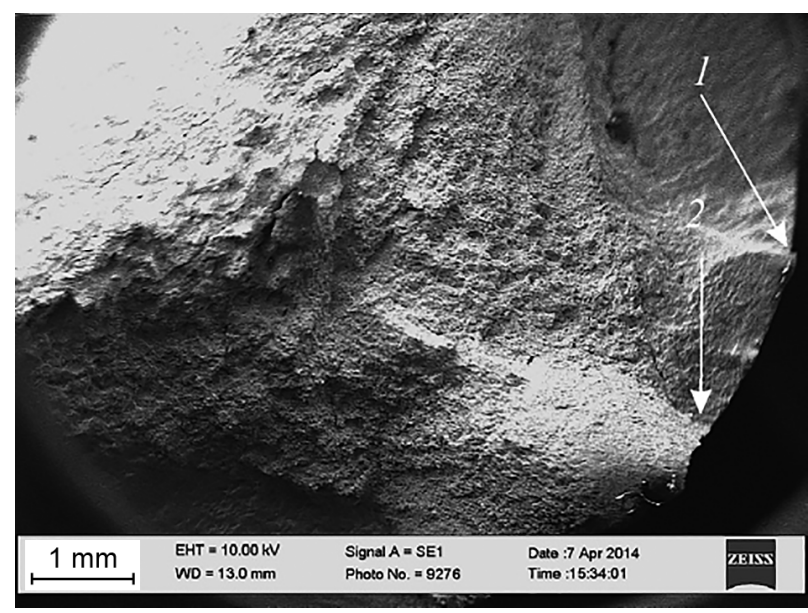

a)

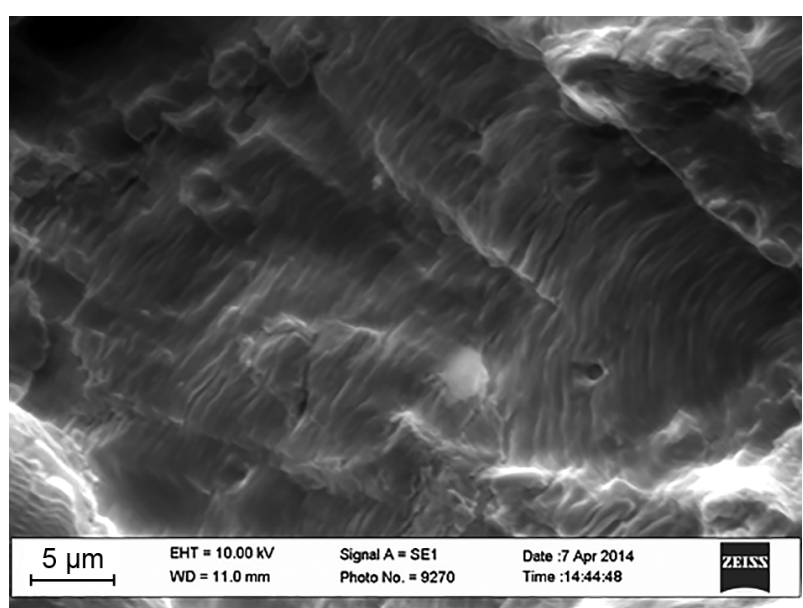

b)

Fig. 5. The place of origin of the cracks from the surface of the specimen and the sickle-front of its propagation into the depth of its section (a) and fatigue fracture surface of Steel 15 in the air (b)

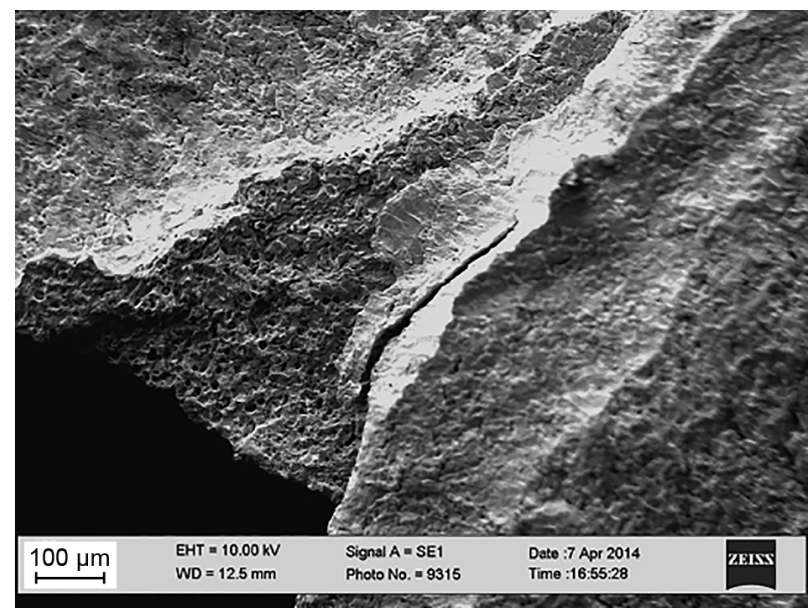

a)

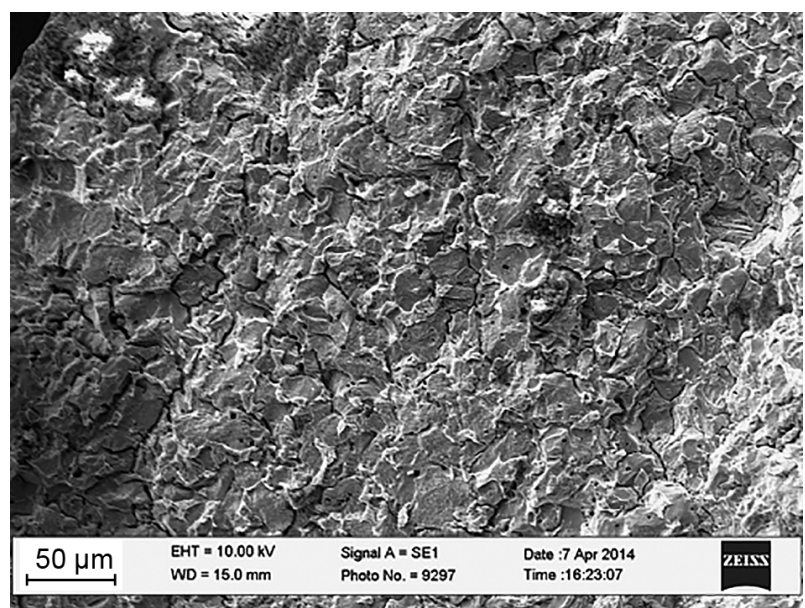

b)

\section{CONCLUSIONS}

The influence of the most aggressive environments of agricultural production on fatigue fracture of agricultural trailers steel elements is analyzed. In particular, in the whole range of applied loads, the resistance of ordinary steels groups under study - St3, St5 and quality steels under study - 10 Steel, 15 Steel, 20 Steel, 25 Steel to the corrosion-fatigue failure in mineral fertilizers environments compared with air decreased significantly.

In a solution of ammonium sulphate, the conditional fatigue endurance limit of steel quality decreased to 2.02 times, in a solution of nitrophosphate - to 2.31 times as compared with air, and to 1.3 and 1.49 times compared to distilled water. In organic fertilizer environment, the

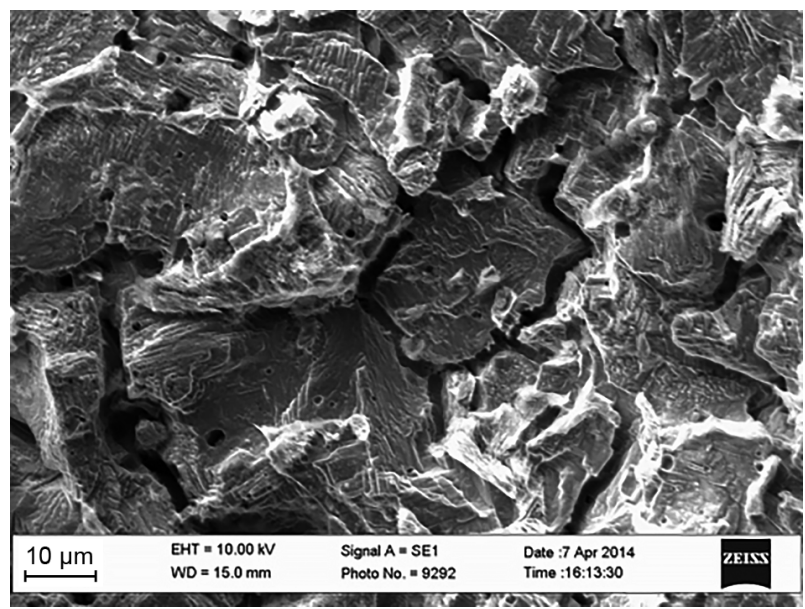

c)

Fig. 6. Fatigue fracture surfaces of Steel 15 in the medium of saturated nitrophosphoric solution: a) $\times 100$, b) $\times 250$, c) $\times 1000$ 
conditional fatigue endurance limit increased to $9 \%$ compared to standard test rainwater. The resistance to the corrosion-fatigue failure of ordinary steels occurred to be lower than quality steels. Less intense impact of organic fertilizers on the fatigue endurance limit of both steels compared to mineral fertilizers was noticed.

\section{REFERENCES}

1. Popovich, P. V.; Slobodyan Z. B.: Corrosion and Electrochemical Behaviors of 20 Steel and St.3 Steel in Ammonium Sulfate and Nitrophoska. Materials Science 2014, 49(6), 819-826.

2. Eker, B.; Yuksel, E.: Solutions to corrosion caused by agricultural chemicals. Trakia Journal of Sciences 2005, $3(7), 1-6$.

3. Gaydar, S.M.: The Wear and Corrosion Resistance of Agricultural Machinery by Means of Nanotechnologies; MSAU: Moscow, 2011; p 416.

4. Popovych, P.V.; Rubak, T.: Complex analysis of reliability of platform of tractor-trailer during operational exploitation. Mechanization of agricultural production. KhNTUSG Bulletin 2010, 93, 411-414.

5. Popovych, P.; Shevchuk, O.; Dzyura, V.; Poberezhna, L.; Dozorskyy, V.; \& Hrytsanchuk, A.: Assessment of the influence of corrosive aggressive cargo transportation on vehicle reliability. International Journal of Engineering Research in Africa 2018, 38, 17-25.

6. Lytvynenko, I. V.; Maruschak, P. O.; Lupenko, S. A.; Popovych, P. V.: Modeling of the ordered surface topography of statically deformed aluminum alloy. Materials Science 2016, 52(1), 113-122.

7. Popovych, P. V.; Lyashuk, O. L.; Shevchuk, O. S.; Tson, O. P.; Poberezhna, L. Y.; Bortnyk, I. M.: Influence of organic operation environment on corrosion properties of metal structure materials of vehicles. INMATEH-Agricultural Engineering 2017, 52(2), 113-118.

8. Popovych P. V.; Lyashuk O. L.; Murovanyi I. S.; Dzyura V. O.; Shevchuk O. S.; Myndyuk V. D.: The service life evaluation of fertilizer spreaders undercarriages. INMATEH-Agricultural Engineering 2016, 50(3), 39-46.

9. Barna, R. A.; Popovych, P. V.: Influence of operating media on the fatigue fracture of steels for elements of agricultural machines. Materials Science 2014, 50(3), 377-380.

10. Hewko, B. M.; Popovich, P. V.; Diachun, A. Y.; Lyashuk, O. L.; Liubachivskyi, R. O.: The study of bulk material kinematics in a screw conveyor-mixer. INMATEH-Agricultural Engineering. 2015, 47(3) 156-163.

11. Oki, M.; Anawe, P. A.: A review of corrosion in agricultural industries. Physical Science International Journal 2015, 216-222.

12. Poberezhnyi, L. Y., Marushchak, P. O., Sorochak, A. P., Draganovska, D., Hrytsanchuk, A. V., \& Mishchuk, B. V.: Corrosive and mechanical degradation of pipelines in acid soils. Strength of Materials 2017, 49(4), 539-549.

13. Poberezhny, L.; Maruschak, P.; Hrytsanchuk, A.; Poberezhna, L.; Prentkovskis, O.; Stanetsky, A.: Impact of gas hydrates and long-term operation on fatigue characteristics of pipeline steels. In Procedia Engineering. TRANSBALTICA 2017: Transportation science and technology: proceedings of the $10^{\text {th }}$ international scientific conference, Gediminas Technical University, Vilnius, Lithuania May 4-5, 2017, pp. 356-362.

14. Maruschak, P.; Poberezny, L.; Prentkovskis, O.; Bishchak, R.; Sorochak, A.; Baran, D.: Physical and mechanical aspects of corrosion damage of distribution gas pipelines after long-term operation. Journal of failure analysis and prevention 2018, 18(3), 562-567.

15. Marushchak, P. O.; Salo, U. V.; Bishchak, R. T.; Poberezhnyi, L. Y.: Study of main gas pipeline steel strain hardening after prolonged operation. Chemical and Petroleum Engineering 2014, 50(1-2), 58-61.

16. Valor, A.; Caleyo, F.; Hallen, J. M.; Velázquez, J. C.: Reliability assessment of buried pipelines based on different corrosion rate models. Corrosion Science 2013, 66, 78-87.

17. Poberezhny, L.; Hrytsanchuk, A.; Hrytsuliak, G.; Poberezhna, L.; Kosmii, M.: Influence of hydrate formation and wall shear stress on the corrosion rate of industrial pipeline materials. Koroze a ochrana materialu 2018, 62(4), 121-128.

18. Poberezhny, L.; Maruschak, P.; Hrytsanchuk, A.; Mischuk, B.; Draganovska, D.; Poberezhna, L.: Impact of AC current density on material corrosion of distribution pipelines. Koroze a ochrana materialu 2017, 61(5), 178-184.

19. Popovych P. Peculiarities of Corrosion and Corrosion Fatigue Behavior of 20 Steel in Water Environments of Mineral and Organic Fertilizers, Corrosion and Corrosion Resistance of Materials (Corrosion-2014). Physical and Chemical Mechanics of Materials 2014, 2(12), 833-838.

20. Sokil, B.; Lyashuk, O. L.; Sokil, M.; Popovich, P. V.; Vovk, Y. Y.; Perenchuk, O. Z.: Dynamic Effect of Cushion Part of Wheeled Vehicles on Their Steerability, Corrosion Fatigue of Metals and Alloys; Spolom: Lviv, 2008; p 304.

21. Gangloff, R. P.: Environmental cracking-corrosion fatigue. ASTM MANUAL SERIES MNL. 1995, 253-271.

22. Barna, R. A., Popovych, P. V., \& Vovk, R. I.: Influence of the working media on the cyclic crack resistance of steels for elements of agricultural machines. Materials Science 2015, 50(4), 621-625.

23. Tsyrul'nyk, O. T.; Bassarab, A. I.: Structural sensitivity of steels to corrosion-mechanical fracture under conditions of fatigue and cavitation. Materials Science 1999, 35(4), 581-586.

24. Iacoviello, F.; Di Cocco, V.: Fatigue crack paths in ferritic-perlitic ductile cast irons. In Atti del Convegno Internazionale International Conference on Fatigue Crack Paths, Parma Cassino (FR), ITALY, 2013; 116.

25. Korda, A. A.; Mutoh, Y.; Miyashita, Y.; Sadasue, T.; Mannan, S. L.: In situ observation of fatigue crack retardation in banded ferrite-pearlite microstructure due to crack branching. Scripta Materialia 2006, 54(11), 1835-1840.

26. Miyazaki, K.; Kanno, S.; Ishiwata, M.; Hasegawa, K.; Ahn, S. H.; Ando, K.: Fracture behavior of carbon steel pipe with local wall thinning subjected to bending load. Nuclear Engineering and Design 1999, 191(2), 195-204.

27. Kanninen, M. F., Broek, D., Marschall, C. W., Rybicki, E. F., Sampath, S. G., Simonen, F. A., \& Wilkowski, G. M.: Mechanical fracture predictions for sensitized stainless steel piping with circumferential cracks. Battelle Columbus Labs, OH (USA). 1976, 12, 24.

28. Maruschak, P.; Panin, S.; Danyliuk, I.; Poberezhnyi, L.; Pyrig, T.; Bishchak, R.; Vlasov, I.: Structural and mechanical defects of materials of offshore and onshore main 
gas pipelines after long-term operation. Open Engineering 2015, 1, 365-372

29. Poberezhnyi, L. Y.; Marushchak, P. O.; Sorochak, A. P.; Draganovska, D.; Hrytsanchuk, A. V.; Mishchuk, B. V.: Corrosive and mechanical degradation of pipelines in acid soils. Strength of Materials 2017, 49(4), 539-549.

30. Poberezhny, L.; Hrytsanchuk, A.; Okipnyi, I.; Poberezhna, L.; Stanetsky, A.; Fedchyshyn, N.: Minimizing losses during natural gas transportation. Strojnicky časopisJournal of Mechanical Engineering 2019, 69(1), 97-108.
31. Zheng, J. Y.; Zhang, B. J.; Liu, P. F.; Wu, L. L.: Failure analysis and safety evaluation of buried pipeline due to deflection of landslide process. Engineering Failure Analysis 2012, 25, 156-168.

32. Pobereznyi, L. Y.; Poberezhna, L. Y.; Maruschak, P. O.; Panin, S. V. :Assessment of Potential Environmental Risks from Saline Soils Subsidence. In IOP Conference Series: Earth and Environmental Science, IOP Publishing, 2015; 50(1), p. 012046. 